\title{
IS IT ONLY A MECHANICAL MATTER? HISTOLOGIC MODIFICATIONS OF THE AORTA UNDERLYING EXTERNAL BANDING
}

Eugenio Neri, MD, ${ }^{\mathrm{a}}$ Massimo Massetti, MD, ${ }^{\mathrm{a}}$ Piero Tanganelli, MD, ${ }^{\mathrm{b}}$ Gianni Capannini, MD, ${ }^{\mathrm{a}}$ Enrico Carone, MD, ${ }^{\mathrm{a}}$ Alberto Tripodi, MD, ${ }^{a}$ Enrico Tucci, MD, ${ }^{a}$ and Carlo Sassi, MD,${ }^{a}$ Siena, Italy

Supported aortoplasty is a technique advocated for moderate dilatation of the ascending aorta when a less radical treatment than aortic graft replacement is sought. ${ }^{1}$ This procedure, which addresses the mechanical components of aortic dilatation, fulfills the Laplace criteria for mural wall stress reduction by counteracting the action of blood pressure on aortic tissue. Aortoplasty restores a normal aortic diameter, whereas external banding reduces the circumferential stress by restoring the aortic wall thickness and thus preventing further dilatation. We present here observations in the cases of 2 patients who had undergone aortic valve replacement and supported aortoplasty years before and in whom a false aneurysm of the ascending aorta developed.

\section{Clinical summaries}

PATIENT 1. A symptom-free 65-year-old hypertensive man with dilatation of the superior mediastinum found in a chest $\mathrm{x}$ ray film was discovered to have a false aneurysm affecting the ascending aorta. Seven years before the patient had undergone prosthetic aortic valve replacement and supported aortoplasty for severe aortic stenosis and moderate dilatation of the ascending aorta. As indicated in the operative record, a 25-mm St Jude Medical bileaflet prosthetic aortic valve (St Jude Medical Inc, Minneapolis, Minn) was inserted with pledgetsupported everting sutures in an intra-annular position. Operative technique included the excision of an oval portion of the anterior aortic wall, beginning at the bottom of the noncoronary sinus and extending throughout the entire dilated portion of the ascending aorta, and inclusion of the entire involved aortic segment in a well-fitted Dacron vascular prosthesis, anchored proximally to the aortic anulus and distally to the anterior aortic wall beyond the dilated portion. At the time of the operation the diameter of the aorta was $45 \mathrm{~mm}$ and the sinuses of Valsalva were spared by the lesion. Reoperation was elected on the basis of contrast computed tomographic examination, which demonstrated that a false aneurysm had devel-

From the Department of Thoracic and Cardiovascular Surgery a and the Institute of Pathological Anatomy and Histology, ${ }^{\mathrm{b}}$ University of Siena, Italy.

Received for publication July 13, 1999; accepted for publication Aug 3, 1999.

Address for reprints: Eugenio Neri, MD, Istituto di Chirurgia Toracica e Cardiovascolare Universitá degli Studi di Siena, Policlinico le Scotte, Viale M. Bracci, 53100 Siena, Italy (E-mail: euxneri@tin.it).

J Thorac Cardiovasc Surg 1999;118:1116-8

Copyright (C) 1999 by Mosby, Inc.

$0022-5223 / 99 \$ 8.00+0 \quad \mathbf{1 2 / 5 4 / 1 0 1 9 1 5}$ oped around the native aorta and reinforcement Dacron cuff. Surgical treatment consisted of aortic root replacement with composite valve grafting and direct coronary reimplantation. Intraoperative inspection showed that the lesion originated from a rupture of the aortic wall located on its posterior aspect, far from the suture line of the aortoplasty. The postoperative course was not complicated, and the patient was discharged on postoperative day 11 . Histopathologic examination of the resected aorta was performed.

PATIENT 2. A severely dilated aortic root was discovered by chance in a 77-year-old hypertensive man during routine chest $\mathrm{x}$-ray examination. Eleven years before the patient had undergone aortic valve replacement for severe aortic stenosis and Dacron graft-supported aortoplasty for poststenotic dilatation of the ascending aorta. A 23-mm Omnicarbon prosthetic aortic valve (Medical Incorporated, Inver Grove Heights, Minn) was inserted with pledget-supported everting sutures in an intra-annular position, and a Dacron graft-supported aortoplasty was performed with the same technique described for patient 1 . Contrast computed tomography revealed the presence of a giant false aneurysm that surrounded the native aorta and reinforcement cuff. The patient was scheduled for surgery. Intraoperative inspection showed that the lesion originated from a tear appearing on the posterolateral aspect of the aorta. The suture line of the aortoplasty was intact. The patient underwent aortic root replacement with composite valve grafting and direct coronary reimplantation. In the postoperative period the patient had cardiac failure that necessitated prolonged inotropic and ventilatory support. The patient was discharged after 35 days in the intensive care unit. He is doing well 1.5 years after the operation. As indicated in the operative record, the diameter of the aorta at the time of the first operation was $50 \mathrm{~mm}$, the sinuses of Valsalva were spared by the lesion, and the aortic wall thickness was $2 \mathrm{~mm}$ at the site of maximal dilatation. Histopathologic examination of the resected aorta was performed.

Histopathologic findings. Histologic examination of aortic tissue specimens, retrieved at reoperation in the area underlying the reinforcement cuff and in the distal ascending aorta not covered by the wrap, were compared with those retrieved at the time of the first operation. Fragments of the aortic wall and reinforcement cuff were embedded in paraffin and histologic slides of the resected aortic wall were stained with hematoxylin and eosin and analyzed with light microscopy. Structural appearance was similar in the 2 cases. The unwrapped part of the aortic wall was basically normal; the medial layers showed neither elastic fragmentation nor reduction in smooth muscle cells (Fig 1,A). Minimal abnormalities 

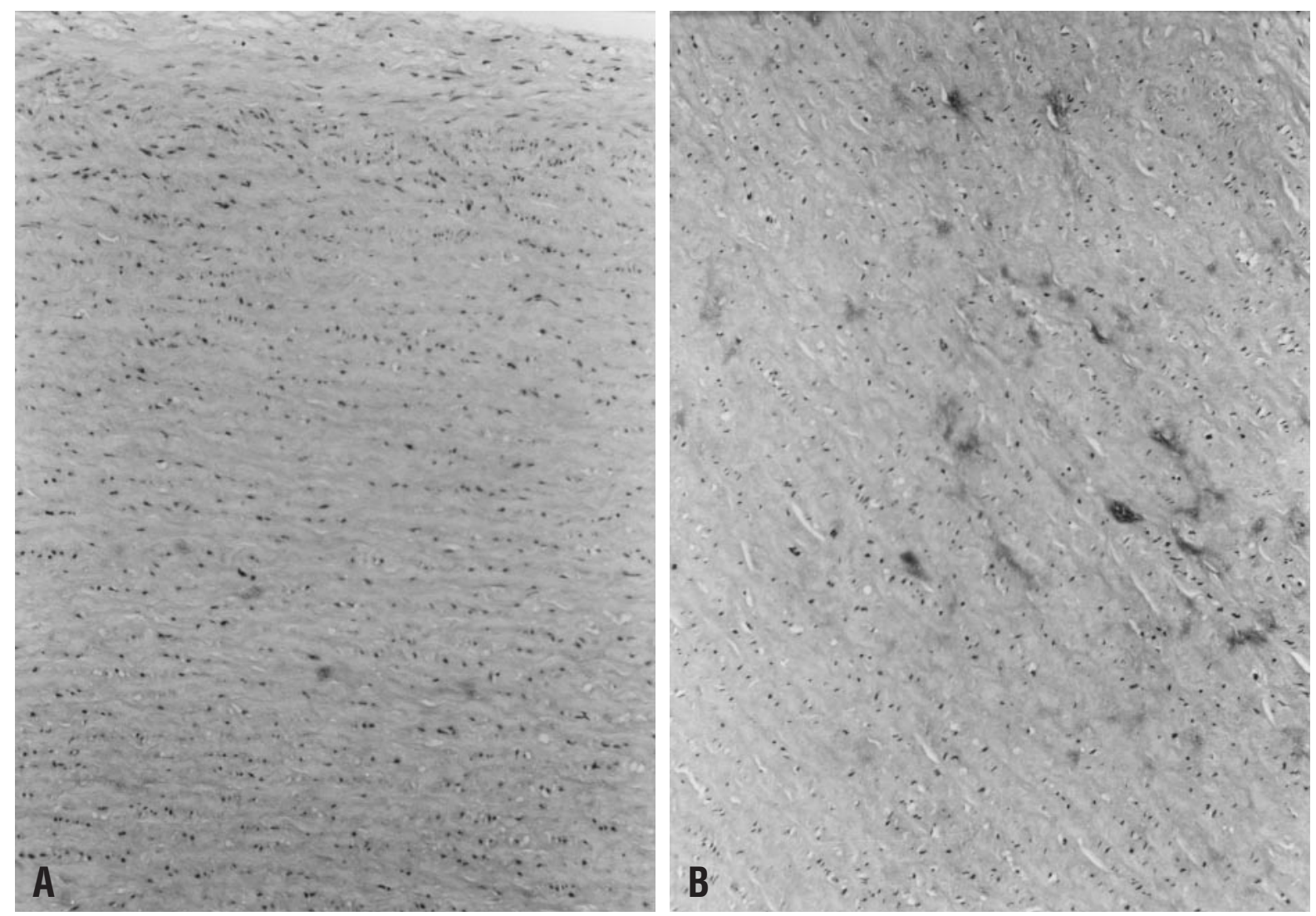

Fig 1. Unwrapped aorta. A, Patient 1. Intimal layer is thin; tunica media shows normally alternating stratification of elastic and muscle layers (hematoxylin and eosin stain; original magnification $\times 10$ ). B, Patient 2 . In some areas microcalcification is visible inside and surrounding some smooth muscle cells (hematoxylin and eosin stain; original magnification $\times 10$ ).

consisted of the presence of microcalcification inside and surrounding smooth muscle cells (Fig 1, B). In both cases the intima was not thickened. Reevaluation of the histologic slides prepared at the time of the first operation did not disclose significant differences in the aortic structure with respect to the later examination of the unwrapped aorta. Conversely, the aortic wall underlying the reinforcement cuff was extremely thin. The structure of the aortic wall was highly sclerotic and the normally existing layers were no longer present (Fig 2, A). This extremely atrophic aortic residual was in direct contact with the Dacron cuff and showed typical cellular and neovascular infiltration and a foreign-body reaction (Fig 2,B).

Discussion. The increase in number of older and high-risk patients with aortic aneurysm associated with aortic valve disease for whom a short aortic crossclamp time is advantageous has resulted in a reevaluation of supported aortoplasty, and good results are reported in the literature..$^{2-4}$ However, some debate still exists regarding whether to wrap the ascending aorta after the aortoplasty procedure. ${ }^{4}$ A recent article $^{5}$ indicates a poor outcome of aortoplasty in patients with moderate dilatation of the ascending aorta and aortic valve regurgitation, with better results observed in those patients with aortic valve stenosis. The existence of defects in the aortic tissue structure in patients with aortic regurgitation has been suggested to explain these different behaviors. In his commentary on the same $\operatorname{article}^{5}$ Robicsek indicates the importance of supported aortoplasty to completely fulfill the Laplace criteria by not only reducing the aortic diameter but also restoring the decreased aortic wall thickness.

The 2 cases presented here gave us the opportunity to observe the histopathologic modifications of the aortic tissue in the area covered by external prosthetic wrapping after operations of supported aortoplasty. The observed histologic changes in the aortic layers suggest that extensive wall degeneration may be induced by the external banding. Interruption of the nutritional vasa vasorum of the aortic tunica media, chronic inflammatory injury sustained by a foreign-body reaction to the prosthetic wrap, or simply the constriction of the aortic wall layers between opposite forces (external banding and aortic pressure) may interfere with the metabolism of the aortic tissue by inducing atrophy and sclerosis. The aorta is thus transformed into a passive conduit with reduced 

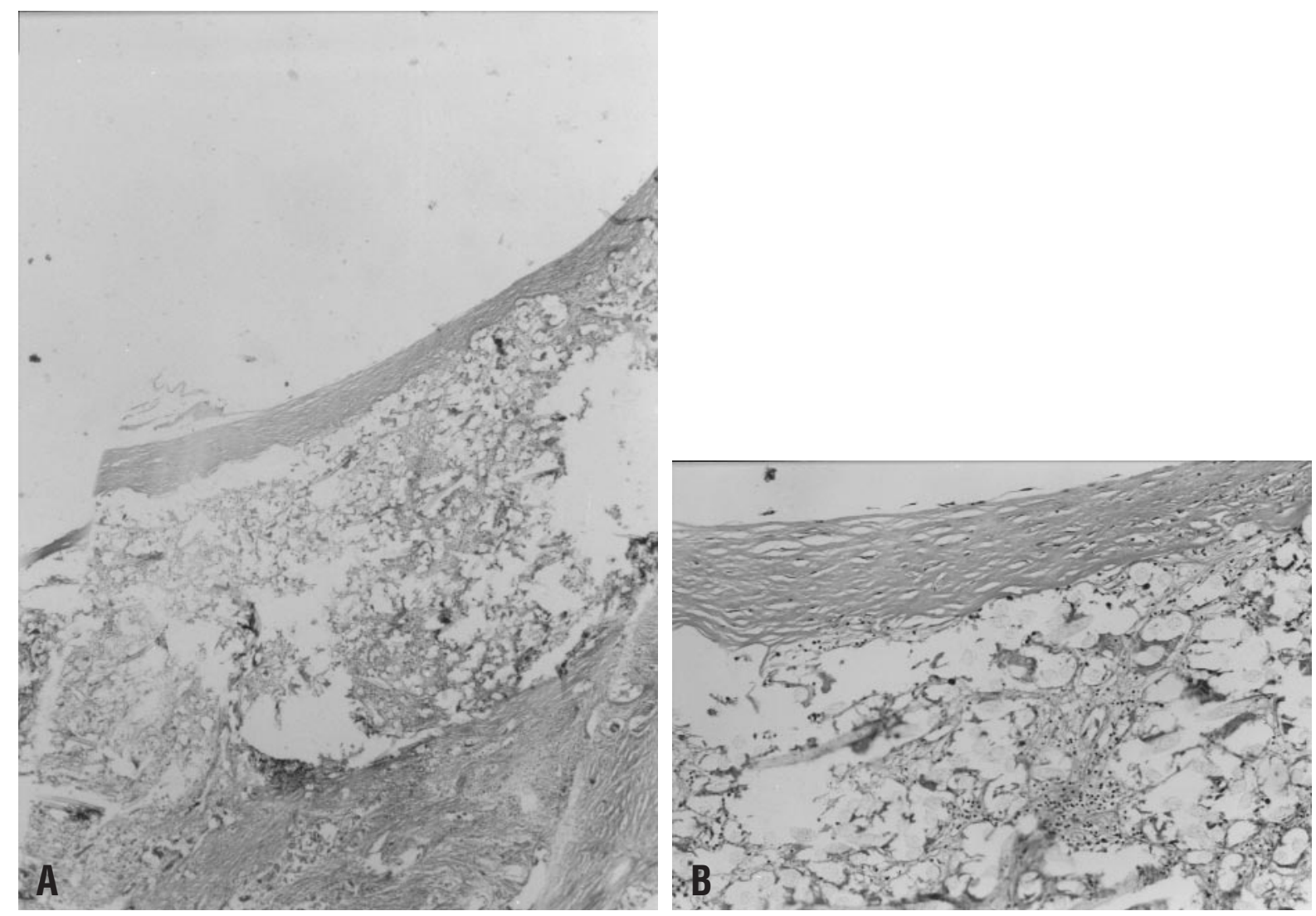

Fig 2. A, Patient 1. Residual aorta joined with top of Dacron cuff and mediastinal stroma (hematoxylin and eosin stain; original magnification $\times 2.5$ ). B, Patient 2. Scleroatrophic aorta and Dacron mesh infiltrated with inflammatory cells (hematoxylin and eosin stain; original magnification $\times 10$ ).

mechanical properties. If confirmed, these effects should lead to the revision of the concept of external reinforcement, which currently takes into account only the physical factors involved in aortic dilatation. The aorta is a viable structure that has its own processes of injury and repair and whose mechanical properties rely solely on its complex architecture and metabolism. Every intervention to relieve aortic dilatation should therefore be evaluated in light of this factor.

\section{REFERENCES}

1. Robicsek F. A new method to treat fusiform aneurysms of the ascending aorta associated with aortic valve disease: an alternative to radical resection. Ann Thorac Surg 1982;34:92-4.
2. Robicsek F, Thubrikar MJ. Conservative operation in the management of annular dilatation and ascending aortic aneurysm. Ann Thorac Surg 1994;57:1672-4.

3. Heikkinen L, Ala-Kulju K. Long-term results of direct aortoplasty for repair of aortic coarctation in adults. Ann Thorac Surg 1990; 49:948-50.

4. Barnett MG, Fiore AC, Vaca KJ, Milligan TW, Barner HB. Tailoring aortoplasty for repair of fusiform ascending aortic aneurysms. Ann Thorac Surg 1995;59:497-501.

5. Mueller XM, Tevaearai HT, Genton CY, Hurni M, Ruchat P, Fischer AP, et al. Drawback of aortoplasty for aneurysm of the ascending aorta associated with aortic valve disease. Ann Thorac Surg 1997;63:762-6; discussion 766-7. 